RELACult - Revista Latino-Americana de Estudos em Cultura e Sociedade

\title{
Os dreadlocks na mira da modernidade: discriminação e resistência. Olhar crítico a partir das teorias pós-coloniais e decoloniais
}

Los dreadlock en la mira de la modernidad: discriminación y resistencia. Mirada critica a partir de las teorías pos-coloniales y decoloniales Dreadlocks in the sights of modernity: discrimination and resistance. Critical look from postcolonial and decolonial theories

Emmanuel Samuel ${ }^{1}$

\section{Resumo}

Este artigo propõe uma análise do preconceito aos dreadlocks no Haiti. Procuramos entender essa manifestação através das teorias pós-coloniais e decoloniais como arcabouços teóricos. Como métodos teóricos, permitem entender a forma em que a modernidade se operacionaliza exercendo um controle sobre os cortes de cabelo e esse controle se faz por meio da discriminação. A discriminação, neste caso, é uma forma de mostrar a hierarquização de qual tipo de padrão de cabelo em relação a outro é aceito. Pois, ao ter os dreadlocks revela a resistência a um confinamento da ideia de beleza, a negação e a desterritorialização dos padrões de beleza oficial-tradicional eurocêntrica. Tal padrão universal de beleza sugere, portanto, como o cabelo tem que ser. Neste cenário, é preciso analisar a operacionalização da modernidade que reivindica ser universalista.

Palavras-chaves:Haiti-dreadlocks-discriminação-modernidade-categorias marginalizadas

\section{Resumen}

Este artículo propone un análisis de la preconcepción a los dreadlocks en Haití. Buscamos entender esa manifestación por medio de las teorías pós-coloniales y decoloniales como marcos teóricos. Como métodos teóricos, permiten entender la forma en la cual la modernidad se operacionaliza ejerciendo un control sobre los cortes de cabello y ese control se hace por medio de la discriminación. La discriminación, en este caso, es una forma de demostrar la jerarquización de cual tipo de cabello en relación a otro que se acepta. Entonces, a los

\footnotetext{
${ }^{1}$ Universidade Federal da Integração Latino-americana, samemmanuel86@yahoo.fr.
} 
dreadlocks es la negación y la desterritorialización de los padrones de belleza oficial-tradicional eurocéntrica. Tal padrón universal de belleza sugiere, por lo tanto, como el cabello tiene que ser. En este senario, es necesario analizar la operacionalización de la modernidad que reivindica ser universalista.

Palabra-clave: Haití-dreadlocks-discriminación-modernidad-categorías marginalizadas

\begin{abstract}
This article proposes an analysis of prejudice against dreadlocks in Haiti. We seek to understand this manifestation through postcolonial and decolonial theories as theoretical frameworks. As theoretical methods, they allow to understand the way in which modernity is operationalized by exercising control over haircuts and this control is done through discrimination. Discrimination, in this case, is a way of showing the hierarchy of which type of hair pattern in relation to another is accepted. For, having dreadlocks reveals the resistance to a confinement of the idea of beauty, the negation and the deterritorialization of the official and traditional Eurocentric beauty standards. Such a universal standard of beauty therefore suggests how hair should be. In this scenario, it is necessary to analyze the operationalization of modernity that claims to be universalist.
\end{abstract}

Key word: Haiti-dreadlocks-discrimination-modernity-marginalized categories

\title{
1. Introdução
}

A discussão proposta neste trabalho, insere-se numa análise crítica que tenta entender a discriminação ao respeito dos dreadlocks. Pretendemos denunciar, neste trabalho, o eurocentrismo mediante a discriminação daqueles que têm Dreadlocks no Haiti. Tal forma de trabalho dialoga com aquilo que pode ser chamado de Teorias do Sul. Sendo assim, não tratase de reproduzir de forma hierárquica as construções que vêm do Norte consideradas como verdadeiras e únicas. É uma denúncia de uma cultura que se pretende universalista na lógica eurocêntrica. Essa concepção apresenta-se como projeto cultural que visa a homogeneização sobre um mesmo padrão cultural, político e econômico. Mediante ferramentas teóricas, procuramos inverter e desconstruir desde a desobediência epistêmica essa visão hegemônica embutida na modernidade e, reconhecer outras experiências fora da construção eurocêntrica; o que, de fato ocorreu ao longo da história dos povos do Sul. Tais experiências são vozes longtemps oprimidas, negadas, invisibilizadas, demonizadas pelo sistema opressor para assim dar legitimidade ao sistema de dominação. Para dar seguimento a essa dominação econômica e militar, esse projeto político e cultural da modernidade ultrapassou as fronteiras europeias atingindo, em um primeiro momento as Américas em 1492 (DUSSEL, 2000), para depois 
atingir a África. Como efeito, tais sociedades e seus principais padrões institucionais são mostras de um legado patrimonialista do ocidente incorporados. O que enfraqueceu os valores e as tradições políticas e culturais do pré-moderno. Diante dessa análise, pretendemos entender o eurocentrismo e sua violência no Haiti.

\section{Os Dreadlocks e a sociedade haitiana}

É comum ver no Haiti o denominado "Rastafarian" ou o chamado "Dreadlock". Sendo primeiro país negro independente, Haiti deixa suas marcas impressas no pensamento político e filosófico no pensamento latino americano, seja através da língua ou das práticas sociais e religiosas do Vaudou. Porém, a operacionalização do eurocentrismo desde o Estado é violenta. Vê-se com muita frequência jovens de distintos gêneros e de categorias sociais diferentes com tal estilo de cabelo. São mulheres e homens, cantoras e cantores, artistas, professores e estudantes. Geralmente, aparecem também os dreadlocks nos grupos de racine ${ }^{2}$. É o que faz com que o Dreadlock é um fenômeno social que chama atenção na nossa sociedade. Essa categoria social está sempre no olhar do Estado. A polícia a vê como um perfil criminal, portanto merece ser castigada; significa que os dreadlocks devem ser cortados. São práticas semelhantes da ditadura militar na era dos Duvalier. Tais casos de violência e de violação da dignidade da pessoa chamam atenção ao I-Dread; o movimento internacional de dreadlocks (LE NOUVELLISTE, 2014). A violência dos policiais em relação a quem tem dreadlocks é uma forma de operacionalização do eurocentrismo no Haiti. Não faltam exemplos para citar, lembrando o caso de várias pessoas entre elas estudantes cujos dreadlocks (LE NOUVELLISTE, 2014) foram cortados.

A forma como os policiais coagem o indivíduo a cortar o cabelo, revela é a materialização do preconceito a partir do Estado, apologia à violência ao corpo que possui Dreadlocks. Isso incentiva e fortalece a discriminação. Além disso, a violência do Estado pontua o preconceito mais vil da modernidade do corpo como violento, ligado a tudo que é negativo. É o imaginário que se tem de um corte fora das fronteiras ocidentais como nato à criminalidade, malvadez, por conseguinte inatos direitos políticos. Basicamente, eles são nãocidadãos e devido a isso passam a qualquer ação de violência do Estado justificada pelo

\footnotetext{
${ }^{2} \mathrm{O}$ gênero Racine surgiu no Haiti na década de 70 durante a ditadura dinástica pai e filho. É um gênero de música de protesta com críticas ao regime do então contra abusos de poder, contra o sistema de repressão, as desigualdades sociais e as instituições internacionais como FMI, Banco Mundial. O gênero Racine é uma combinação das tradições religiosas do "Vaudou" e de Compas.
} 
confinamento de cabelo. A modernidade constrói subjetividades ao ponto de criar um imaginário social. E a pesar de que acabou a sociedade escravocrata, mas ela produz novas formas de naturalização do preconceito. O Estado, por sua a forma como ele opera, mantem a linha divisória entre o tradicional e o moderno no país afro-caribenho.

Levar Dreadlocks aparece, nesse sentido, um perigo diante dos padrões dominantes ao respeito do tipo de cabelo a serem impostos. Mas, também levá-los aparece como uma desobediência no sentido de resistência diante da narrativa ocidental de que tipo de cabelo é aceito ou não e como o cabelo tem que ser. É uma renúncia às etiquetas ocidentais tendo um modelo específico para o cabelo que invisibiliza outras formas de ter o cabelo. Constitui-se uma ruptura na forma de ter o cabelo demonstrando a existência de outras referências em termo de beleza e de moda. Optam, nesse sentido, pela desconstrução dessa maneira de enxergar o mundo. De fato, personagens de distintos horizontes conquistam muitos espaços. Isso constitui uma desterritorialização que tende a romper a ideia de como o indivíduo precisa ter o cabelo para se conformar em determinado espaço. A conquista também de alguns espaços mostra ao mesmo tempo de um novo mundo em relação à beleza totalizadora. Essas categoriais sociais projetam a ideia da beleza diversificada e não de forma fixa. O que constitui também um elemento de reterritorialização com nova localidade. Esse fenômeno se observa tanto na arte como nos grupos musicais: Kompa, Racine, Raggamoffin e também nos espaços acadêmicos: escritores e escritoras, estudantes, professores/as. O último caso ocorre no senado da república onde um senador tinha deadlocks, porém foi solicitado de cortá-los. Isso mostra a intolerância em relação a outros modos de vida a não serem aqueles impostos pelo ocidente.

\section{Colonialidade e discriminação dos dreadlocks}

O avanço do modo de produção capitalista coloca em outro patamar a dominação, de modo que ela torna-se legítima e também se naturaliza. Há toda uma construção que faz com que o reconhecimento de tal cabelo se efetiva. A ideia de qual tipo de cabelo a ser aceito em determinados lugares. Assim, quem não se encaixa no clichê sofre o preconceito conforme às regras determinadas. Tudo isso vem por meio do que é certo ou errado, devido a isso somos submetidos a uma forma de verdade. Ela nos controla através das obrigações e limites. Tudo passa a ser controlado na sociedade na ideia do que deve ser feito e evitado. Um simples olhar constitui uma forma de controle de que estamos bem vestidos ou não. Em relação aos dreadlocks a discriminação se operacionaliza no rechaço nos lugares de frequência, o medo de 
lhes falar por não ser roubado. É a ideia que se constrói sobre os que levam o Dreadlocks como um perfil criminal. A legitimidade de um modelo de cabelo como certo define-se, nesse sentido, pelas regras que buscam indicar como deve ser o cabelo, quais os cortes a tomarem para escapar da repressão. Dessa forma, a sociedade se submete a essas regras que materializam como forma de poder. Esse poder é hierárquico na medida que confere direitos a um tipo de cabelo bem específico. Tal corte indica o grau de legitimidade para frequentar determinados lugares e ocupar determinados cargos. A forma de ter o cabelo torna-se uma distinção que tende a caracterizar quem é um cidadão de bem ou quem desvia as regras da sociedade. O arcabouço teórico foucaultiano tenta explicar como o poder é exercido como um jogo de vigilância exata no acampamento, Foucault alega que:

O acampamento é o diagrama de um poder que age pelo feito de uma visibilidade geral. No urbanismo, na construção das cidades operárias, dos hospitais, dos asilos, das prisões, das casas de educação, esse modelo do acampamento ou pelo menos o princípio que o sustenta: o encaixamento especial das vigilâncias hierarquizadas. (FOUCAULT, 2001, p.197)

A lógica dominante constrói seu discurso em forma de verdade e determina regras claras a serem impostas mediante princípios epistêmicos e estéticos. Foucault, na sua teoria mostra sua preocupação em relação à produção das verdades e quais as regras que valem para produzir determinados discursos sobre determinadas realidades e que constituem as normas dentro de uma sociedade. Nesse cenário, entende-se que essas regras pressupõem o que deve ser dito e quem tem legitimidade para proclamar determinados discursos. São discursos que ganham novas formas. Para Luciana Ballestrin:

Fórmulas históricas clássicas de colonialismo e imperialismo - conquista de territórios, exploração de recursos naturais e mão-de-obra nativa ou escrava, disputas e partilhas geográficas, destruição das culturais locais originárias atualmente estariam sendo reproduzidas com outras roupagens, discursos, ações e estratégias pela preservação e a serviço dos mesmos interesses econômicos e políticos dos países centrais, capitaneadas por diferentes agências, instituições e atores transnacionais. (BALLESTRIN, 2015, p. 194)

Isso faz parte do exercício do poder como exercício de influência. O poder, em tal condição, se exerce e não é visto como uma coisa que pode ser possuída (FOUCAULT, 2001). Ele é subjetivo, está nos lugares e nas pessoas. O poder está nas pessoas significa que no imaginário consciente ou inconsciente das pessoas operacionaliza esse poder. Segundo 
Foucault (2001, p.179) essa relação de poder como forma de verdade é um exercício que depende dos mecanismos considerados como produção de verdade. Pela forma em que somos submetidos ao poder, de certo modo, o poder se situa entre a produção de verdade e pela legitimidade através do direito.

Diante dessa reflexão, entende-se que determinadas categorias em uma sociedade têm um lugar de fala que é visto como um tipo de poder ao qual certas categorias se submetem. Os dreadlock, por exemplo, constituem essa categoria que são categorias marginalizadas e precisam da verdade dos que pensam. A colonização pode ser um exemplo para entender a operacionalização do poder e a produção da verdade. A dicotomia branco/negro constitui-se uma categoria inferior e era considerada como verdade. É o que nos leva a considerar que o rechaço dos dreadlocks no Haiti seria um caráter moderno que é um fenômeno eurocêntrico. O ocidentalismo é a face dominante desse imaginário, é a própria descrição e imagem que a civilização ocidental construiu de si mesma, as formas pelas quais ela se definiu através do discurso do Estado e dos intelectuais e fixou-se como sujeito soberano da modernidade (MIGNOLO, 2003, p.48). Então se trata de toda uma construção simbólica mediante a qual a civilização ocidental se representou a si mesmo e ao resto do mundo a partir de hierarquias sexuais, raciais, linguísticas e espirituais.

Essas hierarquias se constroem conforme a figura universalista. Ela impõe seus valores sobre o vestir, dita as regras comportamentais, a sexualidade, a beleza, corte de cabelo para homem e mulher segundo os padrões de acordo a ela. São comportamentos definidos segundo a cultura política de cada sociedade já que isso está em íntima relação com as condições históricas ligadas à colonização. Isso se entende a partir do momento que a Europa queria impor sua cultura como única. Ao respeito disso, a pensadora Letícia Gómez pensa que:

[...]a cultura política de cada sociedade nutre-se da história, da religião, da origem étnica, da economia, além das situações geográficas que definem a organização de uma sociedade; ou seja, como que as instituições se relacionam na sociedade. São padrões que constituem a cultura dessa sociedade e esses se transmitem de geração em geração (HERAS, 2004, p. 28).

Segundo as análises da autora há uma reprodução das estruturas nas subjetividades. Sendo assim, existe a tradição baseada na família, a relação social cerimonial, a moralidade sexual e a questão da etiqueta que nossas sociedades herdaram. Assim, os usos e 
costumes são da condição colonial na mesma lógica do que é permitido ou não; o que fazia parte da sociedade escravocrata. Por isso, faz-se muita ênfase na diferença de classe como poder simbólico e nas etiquetas formais que exercem uma legitimidade (H. Gómez, 2004). De acordo ao professor Carlos Bauer (2018) em um artigo publicado na revista do departamento de filosofia da Universidad Nacional de la Plata, Haiti deixa suas marcas impressas no pensamento latino-americanocentrista e na história universal, porém ao nosso parecer, a pesar de ser um exemplo de (r)existência através dessa huella, opera ainda o eurocentrismo com graus mais sutis.

Cabe observar o comportamento linear introduzido nas subjetividades. A igreja católica poderia ser outra esfera de intolerância porque ela teve seu monopólio nas colônias americanas, devido a isso nenhuma outra religião foi permitida. O que faz com que qualquer tentativa de expressão de outras formas de religião dentro da colônia era punida. Faz parte de uma ordem linear que deve evitar qualquer desvio. Sendo assim, a intolerância foi o resultado dessa hegemonia. Por isso qualquer ato de desobediência ou dissidência era passível ao castigo. No decorrer do tempo, a intolerância integra nossa cultura política. Nos tornamos intolerantes não só desde o ponto de vista religioso, mas também em relação a outras ideias, outras formas diferentes de organizar e de pensar.

Tudo isso está em decorrência às globalidades: o sistema-mundo. Esse sistemamundo pretende-se civilizador com a missão de expandir-se para os povos sem luz. Então, levar a luz para esses povos se vê como uma tarefa ética. A tarefa enquanto povos escolhidos, é descobrir os outros e levar o evangelho. A religião desempenha um papel relevante. Por isso que os colonizadores são interessados a colocar sua religião para poder dominar sendo um aparato ideológico. Pois, a religião serve, neste sentido, como aparato ideológico para assimilar a cultura do branco e impôr uma estrutura a caráter imperialista. São estruturas mentais eurocêntricas partindo da concepção do que é bom e do que é ruim para manter a ordem vigente, a sociedade escravocrata. Tal fato revela a ideia de considerar-se o centro do mundo. É um processo sistemático e continuado. Ele consiste em submeter os nativos, colonizar o ser humano e a natureza. Foi aí começou a globalização devido a seu caráter expansivo. O contato entre colonizadores e colonizados é uma relação desigual pelo fato que o colonizador se auto-define como branco, o que o torna superior. Sendo uma relação desigual, desenvolve-se uma relação de dominação. Essa dominação se observa tanto na forma como o colonizado é tratado, mas também seus recursos são despojados em prol do 
capital e do mercado mundial. A intolerância instaura-se na ideia (sexualizada, racializada) da cor ao ponto de que os nativos não são tratados como humanos senão como seres inferiores. Intolerância que se manifesta ao respeito do modo de produção local e à religião.

O projeto europeu ao ultrapassar a suas fronteiras desenvolve mecanismo de réplica. Faz parte do processo de desterritorialização inerente ao capitalismo como sinala Serge Latouche (1994). É preciso criar uma vigilância territorial para o exercício do poder. Isso ocasiona a destruição do modo de produção dos povos e a apropriação das terras, dos metais como ouro, prata, artefato e joia. A Espanha já vira nesse então, o (HEILBRONER, 1981) país mais poderoso por conta dos metais saqueados nas Américas. Investem no seu exército e na compra de navios; quanto mais metais um país tinha, se quantifica o tamanho de sua riqueza e de seu poder. Esse raciocínio mostra quão relevante é este período para Europa porque os metais no então era uma forma de troca para qualquer coisa sendo o dinheiro do mundo. Europa passava pela escassez de ouro e de prata em barra, assim a quantidade de metais é uma expressão de poder. Então, isso vira um padrão; pois países que queriam aumentar sua reserva em ouro, entravam no comércio exterior entre América e África. Aí expandiu-se o sistema-mundo e América Latina passa a integrar a modernidade. Essa modernidade pretende-se emancipadora, um estado de maturidade enraizado no esforço da razão e essa razão deve levar ao progresso e desenvolvimento dos subdesenvolvidos. O filósofo Enrique Dussel (2000, p.46,) argumenta que: "Denominamos a esta visión "eurocéntrica" porque indica como punto de partida de la "Modernidad" fenómenos intraeuropeos, y el desarrollo posterior no necesita más que Europa para explicar el proceso". Isso marca o début de um mundo desenhado pelo europeu. Também na afirmação de Dussel, ele deixa entender uma Europa que coloca a si mesmo no centro dos acontecimentos mundiais como se fosse a única civilização. O que revela que História faz-se unicamente na Europa, portanto não há como falar de História unidirecional antes dessa Europa porque ela surge com o sistema-mundo, em 1492.

Esse olhar eurocêntrico expõe a visão de que Europa se descobre e se explica. Não há, para tal concepção, a influência de outros povos. Pode chegar na conclusão de que construíram uma civilização e construíram sua realidade. $\mathrm{O}$ eurocentrismo como conceito tenta ver Europa como centro de produção de conhecimento e de saberes. Novas identidades como indígenas, negros, mestiços e brancos, surgiram nesse contexto na América. Os conceitos de raça são uma construção que têm a ver com a colonização (ANIBAL, 2005). 
Nasce nessa concepção a hierarquização social da cor que leva a dicotomia entre branco e negro. O branco representa pureza, perfeição; por conseguinte é padrão de beleza de tudo que é belo, inteligente, desenvolvido. Ao parecer, o branco se auto-entende como mais desenvolvido e superior. Vê a necessidade até a obrigação moral de desenvolver os bárbaros; é a hierarquização da cor criando diferença entre a cor do branco e a do negro/indígena, mas também um mecanismo para consolidar as relações de dominação. Nessa postura, quem faz a classificação é o europeu; ou seja, ele projeta o não-europeu e o constrói como outro. Devido a essa classificação, predomina dentro da colônia o racismo. A experiência colonial mostra a cultura dos colonizadores como uma cultura desenvolvida; enquanto a cultura do negro/indígena como subdesenvolvida. As imagens corporais dos brancos associam-se como normais, lindas, avançadas; enquanto as imagens corporais do negro como uma deformação, portanto é patológica, feia e retrasada. Quer dizer, a cor negra é vinculada ao mau, a tudo que é satânico, o que era necessário que ele fosse batizado; já que não tinha alma. Vê-se aí, antes de tudo, a justificação do branco sendo iluminado, civilizado e que o outro necessitava desenvolver-se para ter essas mesmas características empregando a violência. É a pretensão do sujeito universal ${ }^{3}$ como acabamos de explicar. $\mathrm{O}$ egocentrismo do sujeito universal o torna a um ponto que não consegue olhar o outro, vê-lo com suas diferenças. Considera-se como figura singular, porque entende tudo a partir dele, de sua própria referência. Então, quem não tem suas características é discriminado, ao final, nega o outro e se afirma como ser. É a afirmação de si como sujeito e a negação do outro como não-ser. Esse outro, ao não ter sua cor, sua língua e sua cultura, é considerado como satanás. Eis a razão pela qual os negros e os indígenas necessitavam ser batizados para tirar o espírito maldito. No decorrer do tempo, essas ideias foram se construindo e consolidando-se, não só no período da escravização, mas também ao longo do tempo e até nos grandes centros acadêmicos ocidentais. Cabe recordar que teses científicas alegavam também que existe uma superioridade entre as raças. É uma forma para manter o discurso cientificizando-o.

No período colonial, o padrão estabelecido faz uso da coerção para impôr a língua do colonizador como língua superior; já que para esse sujeito universal, como já destacado, tudo que lhe pertence é universal, pois isso faz com que o escravo tinha que aprender e falar sua língua, e impô-la como hegemônica. No caso do Haiti, a fronteira existe entre o francês e

\footnotetext{
3 É a ideia de um sujeito que se entende como único e singular. É uma apropriação para referir-se à discriminação. O universalismo é um conceito empregado por Joan Scott na revista de Princeton University como crítica nas relações sociais de gênero.
} 
o crioulo haitiano. A língua colonizadora é a língua culta e a outra é a língua selvagem. O que implica que falar o francês no Haiti, é um falar certo, elegante, civilizado, enquanto o falar crioulo é não escolarizado, portanto é estigmatizado.

Então, a economia, o sistema religioso, as línguas do outro foram destruídos. Tal concepção indica a intolerância dos europeus. Para entender a nossa cultura de intolerância, precisamos entender essas formas de discriminação, de intolerância que constituem a cultura política. Nossa identidade é construída pelas estruturas da colonização e da cultura crioula. Nós herdamos essas formas de opressão de forma que atuamos até hoje como pessoas que detêm os valores universais e prontas a colocá-las sobre aquelas, de acordo a nosso parecer, não se encaixam. Queremos ver o outro como nós, ao contrário passa a ser discriminado. Nossa sociedade considera os que têm dreads como delinquentes porque eles não se enquadram no perfil ocidental com o cabelo "normal" tal como quiser o sujeito universal. Sendo assim, há todo um mecanismo violento para deixar saber a pessoa que ela não é normal. A sociedade passa a controlar o comportamento mediante a discriminação, a repressão, o rechaço de modo a colocar os padrões sociais de beleza e de corte de cabelo.

Não há como pensar as formas de discriminação sem pensar na modernidade porque ela está embutida nela. A discriminação tem a função de um micropoder que coage o outro mediante regras claras. Perante a essa opressão, a afirmação do outro é demonstrar que há outras formas de viver e de pensar, portanto isso mostra também que a narrativa europeia não é uma construção histórica; o que deixa claro que não é algo natural como se pretende

\section{Resistências e derrotas: a transmodernidade}

A modernidade opera em todas as esferas para deixar seu legado patrimonialista. Porém, sempre houve revoltas, resistência dos territórios, dos grupos colonizados e revoltas epistêmicas também, o que significa que não só os dreadlocks. A revolução haitiana de 1790 e sua independência em 1804 constitui-se em uma ruptura epistemológica. De fato, ela coloca em xeque os valores eurocêntricos e ressignifica o conceito de igualdade e se liberta. Nesse cenário, constitui junto, aos demais movimentos de independência do século XIX na região, um projeto contra-hegemônico político, cultural e de reorganização da economia de forma inclusiva. No início do século $\mathrm{XX}$, a revolução mexicana e a revolução russa são outros exemplos de derrotas do projeto da modernidade. Em um programa gravado e publicado em 2018, o pensador Henrique Dussel explica como ocorrem debates acadêmicos no centro para 
questionar a modernidade. Conforme a isso, surgem as teorias críticas com Herbert Marcus, Jean Paul Sartre. Enquanto isso, no Sul segundo o acadêmico, lia-se autores que pensam desde o oprimido como Frantz Fanon, Pedagogia do oprimido de Paulo Freire, Fals Borda sobre Sociologia da libertação, boom literário com Alejo Charpentier. Formulou-se também a Teoria da Dependência em que os autores latino-americanos questionam os teóricos clássicos da economia sobre a divisão internacional do trabalho mediante os conceitos de vantagem relativa e absoluta.

As produções epistêmicas voltadas ao lugar do negro como sujeito epistêmico, mostra o rechaço de uma ciência com pretensão totalizadora que pretende produzir conhecimento em qualquer espaço para qualquer época. Os estudiosos antilhanos e africanos formularam "La Négritude", que segundo Senghor (1961, p.9), é a "soma de todos os valores africanos". O giro em que as derrotas dão início vem desde uma primeira obra do século XIX do autor haitiano Anténor Firmin em um debate que ele entrou com Joseph Arthur de Gobineau na obra de "Desigualdade da raça humana publicado em 1855 e a resposta do autor haitiano é "Igualdade das raças humanas"; livro publicado em 1885. Partindo desse debate, os autores caribenhos e africanos Jean Price Mars (Haiti), Aimé Césaire (Martinica), Léopold Sédar Senghor (Senegal), na egiptologia e na antropologia Cheikh Anta Diop (Senegal) que desconstrói o branqueamento da história. É nesse cenário que se formulou o Pan-africanismo ${ }^{4}$. Surge também o pensamento da Teoria da libertação com Gustavo Gutiérrez. A revolução cubana com Fidel que impactou o pensamento crítico nos espaços acadêmicos latinosamericanos, mas também constitui uma derrota para o ocidente já que representa uma experiência diferente do ocidente segundo as receitas como Estado. E lia-se ao mesmo tempo Che Guevara que aportou coisas diferentes das experiências europeias em relação à liberdade, e também Memmy na obra O colonizador e colonizado (1991).

A ruptura epistemológica suscita debates e questionamentos nos estudiosos latino americanos. Por isso a obra de Augusto Salazár Bondy tenta perguntar em torno de que se: Existe la filosofia de nuestra América (1967)? A resposta foi não devido a nossa cultura dominada segundo sua resposta. É esse conjunto de obras que abrem caminho para entender a dicotomia do ser/não-ser; o não-ser que é o pobre. Pois, são outros tipos de oprimidos. Mas também pelos acontecimentos dos movimentos populares na região durante a crise econômica. É neste contexto surgiu a filosofia da libertação devido aos movimentos de

\footnotetext{
${ }^{4}$ Grifo meu
} 
libertação. O conceito de libertação, de acordo com Dussel (2018), ele é político e está ligado a esses movimentos de libertação é o não-ser que chega a ser como na Argélia Frente de Libertação de Argélia e em vários países desta região. Seguidas dessa frente seguem na América- Latina movimentos como Frente de Farabundo Martí de Libertação Nacional (FMLN) no El Salvador, Frente Sandinista de Libertação na Nicarágua, Exército Zapatista de Libertação no México. A filosofia da libertação teve uma luta política no meio das ditaduras militares, o que mais tarde deu lugar a vários governos progressistas. Mas também essa rama epistêmica transformou-se em um dos pilares da "Descolonização epistêmica" segundo o filósofo.

A necessidade de descolonizar o pensamento vem sendo uma crítica ao eurocentrismo teórico das ciências sociais, inaugura, neste sentido, o projeto do grupo latinoamericano Modernidade/Colonialidade a sua configuração mais recente. O excluído torna-se enunciante, ou seja, as teorias decoloniais conferem um lugar de fala. O que é diferente do discurso moderno europeu porque certas categorias da sociedade não podem ser sujeitos epistêmicos. Para essas teorias, são grupos que não possuem uma razão, uma consciência do fazer e do pensar e uma linguagem capaz de expressar e fazer valer sua cultura; por conseguinte são grupos fora das referências europeias. Então, o grupo Modernidade/Colonialidade surgiu a partir de produções de intelectuais de distintos países da América-Latina dentre os quais se encontram Enrique Dussel, Walter Mignolo, Aníbal Quijano, Santiago Castro Gomez, Immanuel Wallerstein, Edgar Lander. Como forma de resistência, são autores que formulam alternativas epistemológicas críticas ao paradigma eurocêntrico da modernidade. No eixo de sua argumentação a ideia de colonialidade é um fenômeno ligado e também é parte constitutiva da globalidade modernidade. Devido a isso, o grupo Modernidade/Colonialidade, a modernidade remonta ao século XVI, período no qual se inicia a colonização na América.

Devido à alta produção do sistema capitalista, vários movimentos de resistência surgiram no século XX como forma de escapar da sociedade de consumo, de ideias, de desejo e de criação de padrões de vida. Com base a isso, surgiu nos anos 60 os movimentos negros nos anos 60, movimentos contracultura, contra os hábitos puritanos como forma de resistência a vida diária: sexualidade, drogas, modas, contra o consumo. Nesse período, aparecem os hippies porque o corte curto representa a ordem, a disciplina como os militares como já salientamos. É nesse cenário, somos levados a observar o preconceito dos dreadlocks no Haiti 
como categoria que está à margem da sociedade, portanto os policiais constituem a mais eficaz articulação para chegar ao universalismo. Diante dessa análise, dá para ver aparatos institucionais, a violência e a construção de uma narrativa são formas sutis pelas quais os movimentos sociais e epistêmicos lutam. São lutas que buscam a diversidade e legitimidade de outras experiências desvelando a modernidade que confere a Europa um lugar de privilégio de produção de discurso como verdade e de consolidação de sua narrativa.

Porém, os movimentos tanto políticos como teóricos de diferentes campos epistêmicos apresentam como característica comum uma resposta crítica a tradição epistemológica ocidental. Para esses intelectuais, a epistemologia moderna impõe-se como a perspectiva única e oficial de conhecimento, negando e inferiorizando todas as outras formas de enxerga o mundo a não ser do ocidente. É uma construção epistêmica que, para os pensadores, reproduz, dentro dos seus domínios de pensamento e prática, as relações de dominação legadas pelo colonialismo. A derrota passa a ter várias denominações - póscoloniais, decoloniais, pan-africanismo, teorias do sul, etc. - essas contribuições teóricas mostram a segmentaridade cultural criada pelos sistemas de representação ocidentais e desconstruir as formas de pensamento e os esquemas de interpretação que definiram a concepção binária entre as zonas coloniais como fontes de cultura a serem estudadas, e o ocidente como a matriz intelectual teórica da humanidade.

\section{Construção da narrativa e sua legitimidade como única e verdadeira na contemporaneidade}

O projeto político e cultural da modernidade ultrapassa as fronteiras da Europa para alcançar as Américas, a Ásia, o Oriente Médio para logo depois atingir a África. Como consequência disso, em todas essas sociedades, o modelo de Estado-nação, os principais padrões institucionais e de beleza foram incorporados. Institui-se a forma como o indivíduo deve vestir de uma maneira específica e quando deve vestir para uma determinada ocasião e determinado lugar. É a ideia do que tem que ser dito e quem tem legitimidade para proclamar esse discurso sobre determinado fenômeno. Tal perspectiva contribui na hierarquização de outros modelos de beleza e foram marginalizados mediante regras claras e definidas, é o que faz com que os Dreadlocks se vêm como outros. Portanto, assistimos nas últimas décadas a indústria cultural euro-norte-americana como que ela impõe-se na propaganda de modas e etiquetas. Assim, a mídia constitui a estrutura ao ponto que tira a consciência da pessoa na 
representação da verdade. Existe a ideia de que determinada informação torna-se hegemônica por isso opera como um bem de consumo.

O professor Paulo Freire (2015) debate a influência da mídia sobre nossa vida, perante isso o conceito de dialogicidade não existe nos noticiários, quer dizer, não se estabelecem as relações causais dos fatos. Ele aponta que num mesmo tempo ocorre uma notícia trás outra por isso que ele aponta:

[...] o extraordinário poder da mídia, da linguagem da televisão, de sua "sintaxe" que reduz a um mesmo plano o passado e o presente e sugere que o que ainda não há já está feito. Mais ainda, que diversifica temáticas no noticiário sem que haja tempo para a reflexão sobre os variados assuntos. (FREIRE, 2012, p.136)

Essa forma de poder que a mídia exerce está relacionado com o modo de produção em que demanda o consumo de tudo: ideias, desejos, bens etc. onde tudo se transforma em mercadoria para a circulação no mercado. É a lógica para o consumo já que ele gera lucro para o capitalismo. Dado ao caráter positivista da mídia, ela deixa entender uma determinada forma de conceber a beleza, o corte de um tipo específico de cabelo é exigido. Requer a homogeneidade ao respeito de um único modelo de cabelo. Então, como estrutura, a mídia constrói a opinião do ouvinte ao tal ponto que ele naturaliza e incorpora os padrões de beleza como valores sociais a partir de uma racionalização. Alienado pela mídia, esse sujeito não dá conta de que é a cultura que faz acreditar em determinados acontecimentos, já que a vida é uma construção social conforme a cada sociedade. Pois, decidir sobre o que é certo ou errado vem de um determinado lugar ligado a nossa história. É a narrativa ocidental que nos dá o sentido de quem somos, o que consideramos como legítimo ou não. A formalidade, as etiquetas são experiências europeias. São experiências que são disseminadas às demais regiões do mundo adquirindo novas configurações tal como salientamos. Esses padrões ocidentais conferem um lugar de privilégio. Buscam, nesse sentido, legitimar-se enquanto padrão dominante para distinguir-se às formas de beleza. Qualquer um que foge dos clichês ocidentais de aparência- cabelo solto, com tranças ao estilo de dreadlocks- não possui uma postura mais próxima ao que a sociedade considera como "normal" conforme aos padrões estabelecidos. Sendo assim, o olho torna-se como forma de controle e gera as preocupações na forma de vestir e de se comportar, etc. 
Essa forma de explicar é uma tentativa de desvelar as formas como a modernidade operacionaliza-se no contexto que estamos estudando. As teorias decoloniais contribuem para tentar entender essa modernidade sendo uma relação de opressão opondo os valores ocidentais a serem impostos como universais no resto do mundo. É a afirmação de um Ocidente enquanto ser e a negação do outro como não-ser. É a ideia de que esse não-ser não tem história, desde o ponto de visto europeu (Freire, 2008), não tem discurso científico dessa modernidade, por conseguinte, não podem ser configurados como atores políticos. Para essa lógica, esses grupos não têm uma linguagem específica. A mídia nessa linha constitui como mecanismos usados pelos opressores e assim reproduzem os padrões sociais de dominação. A herança mantém-se e se define em relações materiais que opõe massa e classe dominante. Nessa relação, a massa passa a ser estigmatizada como sem cultura ignorante e a elite como ser inteligente com referência. Nessa mesma linha, Freire pensa que:

\footnotetext{
Os colonialistas diziam que somente eles tinham cultura. Diziam que antes da sua chegada à África nós não tínhamos História. Que a nossa História começou com a sua vinda. Estas afirmações são falsas, são mentirosas. Eram afirmações necessárias à prática espoliadora que exerciam sobre nós. Para prolongar ao máximo a nossa exploração econômica, eles precisavam tentar a destruição da nossa identidade cultural, negando a nossa cultura, a nossa História (FREIRE, 89, P. 2011).
}

É a partir dessa construção que um padrão de beleza se instala em uma sociedade e é reconhecida como legítima. A mídia na contemporaneidade ajuda a consolidar o discurso cultural do que pode ser beleza ou não e qual tipo de cabelo é aceito.

\section{Corte como padrão e adestramento na sociedade}

Manter uma ordem está a uma verdade que tende a disciplinar uma sociedade por meio de certas fórmulas ou regras. Anda é preciso deslegitimar, o que significa criar uma segmentaridade. Assim, o preconceito pode ser uma forma de controle. no caso que estamos estudando, o corte de cabelo é um mecanismo de controle pelos grupos dominantes. Esse controle se vê na forma em que se mantem o cabelo curto como padrão, ao contrário, as pessoas que fogem desse corte são passíveis à sanção. A sanção exerce um poder disciplinar que visa a normalizar, a adestrar o comportamento. O objetivo dessa normalização é evitar qualquer desvio. Sendo assim, quem não se enquadra é castigado, devido a isso que é preciso estabelecer os padrões. Tal comportamento responde a uma estrutura que tende a estimular o consumo que se faz pela mídia- escrita e televisiva. Tudo isso se inscreve em uma estratégia de um sistema de controle hegemônico. 
O corte do cabelo confere um poder hierárquico. Tal apresenta-se como única experiência de beleza; portanto estabelece-se como padrão a ser imposto. Sendo assim, precisa uma ética no sentido de estabelecer suas regras que fazem com que todos se movem dentre delas. Pois, o indivíduo precisa aprender determinados padrões de corte concebidos como aceitos pela sociedade como beleza e são esses especificamente, por conseguinte, não outros. O indivíduo está sujeitado a obrigações que são o que o moderno desenha de acordo a seus valores. Essas obrigações e limitações são relações sociais de opressão que remonta desde a sociedade escravocrata onde as oligarquias colonialistas negaram ao colonizado todo tipo de direito por meio da escravidão. Essa negação se reproduz através de outras formas na sociedade haitiana, porém operam no mesmo patamar que visa a legitimar um padrão de corte que não sejam os dreads. Então, quem tem referência é só grupos dominantes constituída como modelo a seguir.

\section{Considerações finais}

O preconceito como exercício de poder é a forma de punir aqueles que levam dreadlocks onde a modernidade oculta esse cabelo para legitimar um corte específico. Como sociedade receptora da modernidade, reproduz tal como essa modernidade operou na Europa mediante a classificação de gênero e de sexo, classificação que opõe de uma região a outra, urbano/rural e interior e determinada língua que goza de certa legitimidade em relação a outra. São formas que visam a homogeneidade. O dreadlock é uma reação notória à concepção dominante de corte de cabelo inserido na modernidade. Tal corte apresenta uma resistência que deseja romper com a naturalidade com que atribuímos um valor universal incontestável a beleza ocidental. Por ser considerado como uma beleza subalterna, passa a confrontar o paradigma eurocêntrico hegemônico.

Cabe ver, em contraste com a perspectiva da modernidade, as teorias pós-coloniais e decoloniais apontam para outras experiências que e consideram desde o mundo moderno ocidental, como experiências inferiores. Nessa ótica, essas teorias confrontam a narrativa hegemônica e universalista. Esse giro constitui em se posicionar sobre outro pensar, as práticas políticas e epistêmicas. Isso mostra o caráter alternativo ao paradigma eurocêntrico como experiência global. 


\section{Referências bibliográficas}

BALLESTRIN, Luciana. Democracia e Desigualdade. Revista de Estudos Políticos Vol. 5IN.1ISSN2177-2851, 2015

BAUMAN, Zygmunt. Vida líquida. Editorial Planeta, 4.ed., 2004

BERGER, L.Peter e LUKMANN, Thomas. La construcción social de la realidad, 1. ed., 1968, Buenos Aires

CHOMSKY, Naom. Mídia: propaganda política e manipulação- SP: Editora WMF Martins Fontes

DELEUZE, G. e GUATTARI, F. 1995a. Mil Platôs: capitalismo e esquizofrenia. Vol.1. Rio de Janeiro: Ed. 34.

DUSSEL, Enrique. Europa, modernidad y eurocentrismo. In. LANDER, Edgardo. (comp.) La colonialidad del saber: eurocentrismo y ciencias sociales: perspectivas latinoamericanas. Buenos Aires: CLACSO, 2000, p.41-53

1 Vídeo (26:06). Enrique Dussel habla sobre el movimiento del 68 latinoamericano. Publicado pelo canal C. Paizanni, 2018. Disponível em https://www.youtube.com/watch?v=mGuWcQtBpM0\&t=807s Acesso em: 09/052019.

FIRMIN, Anténor. De l'égalité des races humaines. Anthropologie positive, ville Laval, Québec, p.450. 1885.

FOUCAULT, Michel. Vigiar e punir. Petrópolis: Editora Vozes, 1987. 
FRANCISCO, Carlos Bauer. La huella de Haití, el latino-americanocentrismo y la historia universal. Anais eletrônico do Congresso epistemologias do Sul, V.2, n-1, 2018.

FREIRE, Paulo. Comunicação ou extensão, 17 ed., 2015

A importância do ato de ler- 51. ed.- São Paulo, 2011, V.22

Pedagogia da autonomia. 52 $2^{\text {a }}$ Rio do Janeiro: Paz Terra, 2015

GOBINEAU, De Arthur. Essai sur l'inégalité des races humaines . livres 1 à 4 1853-1855

HEILBRONER, Robert L. Introdução à história das ideias econômicas, 5. ed., Rio de Janeiro, 1981

HERAZ GOMEZ, Leticia. Cultura política y democratización en América Latina. México: REDALYC, 2004

HUNT, E. K. História do pensamento econômico. 2. ed. Rio do Janeiro, 2005

LATOUCHE, Serge. Pequeno tratado do decrescimento Sereno, 2 ed., 1994, São Paulo

MIGNOLO, Walter. DESOBEDIÊNCIA EPISTÊMICA: A OPÇÃO DESCOLONIAL E O SIGNIFICADO DE IDENTIDADE EM POLÍTICA. Duke University, Universidad Andina Simón Bolívar) Traduzido por: Angela Lopes Norte. Cadernos de Letras da UFF Dossiê: Literatura, língua e identidade, no 34, p. 287-324, 2008

DESAFIOS DECOLONIAIS HOJE . EPISTEMOLOGIAS DO SUL, Foz do Iguaçu/ PR, 1, 2017. PP. 12-32,

QUIJANO, Anibal. Colonialidade do poder, eurocentrismo e América-Latina. A colonialidade do saber: eurocentrismo e ciências sociais. Perspectivas latino-americanas. CLACSO, Buenos Aires, Argentina. setembro 2005. pp.227-278. Disponível em: http://bibliotecavirtual.clacso.org.ar/ar/libros/lander/pt/Quijano.rtf

ROITMAN ROSENMANN, Marcos. La estructura social en el orden oligárquico. In: . Pensar América Latina. El desarrollo de la sociología latinoamericana. Buenos Aires, CLACSO, 2008.

SCOTT, W. Joan. O enigma da igualdade, Princeton University, 1999. Disponível: http://www.scielo.br/pdf/ref/v13n1/a02v13n1.pdf Consultado em: 25/05/2019

SENGHOR, Leopold Sédar. Négritude et humanisme (1964), Paris, Éditions du Seuil, 1961, p. 9. Asso em le 31/06 2019. URL : http://journals.openedition.org/etudesafricaines/14446 
ST JUSTE, Edrid. Chasse aux dreads: Tout le monde ne peut pas être «tèt kale»https://lenouvelliste.com/lenouvelliste/article/138854/Chasse-aux-dreads-Tout-lemonde-ne-peut-pas-etre-tet-kaleAcesso em 05/072019 